\title{
Prospects and Constraints to Attaining Universal Access to Modern Energy in Malawi: A Review
}

\author{
Hope Baxter Chamdimba ${ }^{1, ~ *, ~ G a d ~ R e u b e n ~ M u g a g g a ~}{ }^{2}$, Elias Ako ${ }^{2}$ \\ ${ }^{1}$ Energy Resources Department, Ndata School of Climate and Earth Sciences, Malawi University of Science and Technology (MUST), \\ Thyolo, Malawi \\ ${ }^{2}$ Energy Technology Department, School of Engineering, Kenyatta University, Nairobi, Kenya
}

\section{Email address:}

hbchamdimba@gmail.com (H. B. Chamdimba),gadrobben@gmail.com (G. R. Mugagga), ako.elias@ku.ac.ke(E. Ako)

${ }^{*}$ Corresponding author

\section{To cite this article:}

Hope Baxter Chamdimba, Gad Reuben Mugagga, Elias Ako. Prospects and Constraints to Attaining Universal Access to Modern Energy in Malawi: A Review. International Journal of Sustainable and Green Energy. Vol. 10, No. 1, 2021, pp. 19-27. doi: 10.11648/j.ijrse.20211001.14

Received: February 3, 2021; Accepted: February 10, 2021; Published: February 26, 2021

\begin{abstract}
The Malawi Government regards energy as a life blood of the economy and as such a number of national policy documents have emphasized energy as one of the national priority areas that demand urgent intervention by the government and stakeholders. There is also a consensus that ensuring universal access to modern energy in an energy deficit country will also help improve living standards of people in line with national and global goals. Through a 2018 National Energy Policy, Malawi effectively domesticated the Sustainable Development Goal Seven and the Sustainable Energy for All objectives which among others seek to ensure universal access to modern energy by the year 2030. However, now in the last decade of the 2030 agenda, the country is not yet on the path to achieving the universal access to energy goal despite of having numerous opportunities for reversing the energy poverty trends. Doing a post-mortem is of essence in order to determine prospects and constraints to achievement of the national energy goals and objectives regarding universal access to modern energy. Therefore, this paper seeks to discuss the status of energy access to modern energy in the country, the prospects and constraints in relation to energy policy, regulatory environment, institutional capacity, energy resource, capital investment, technology and human resource.
\end{abstract}

Keywords: Energy Constraints, Energy Prospects, Malawi, Modern Energy, Universal Access

\section{Introduction}

Malawi, a Sub-Saharan country is one of the least developed countries around the globe considering that a good segment of the population is still in extreme poverty [1]. In an effort to reverse similar trends, the role of modern energy has proved to be so crucial in many other countries. This is particularly so because access to reliable, affordable and modern forms of energy plays an essential role in socio-economic development and improving the quality of life $[2,3]$. Currently, the world depends on energy for almost everything and therefore improving access to modern energy shall be pivotal in driving developing countries such as Malawi to sustainable economic growth $[4,5]$. The Government of Malawi (GoM) considers energy as the lifeblood of national economy due to its essentiality to most goods and services in a modern world $[4,6]$.
In pursuit of attaining universal access to energy, the United Nations came up with the ambitious Sustainable Development Goal Seven (SDG 7) which seeks to ensure access to affordable, reliable, sustainable and modern energy for all by the year 2030 [7]. The SDG 7 is also reinforced by the Sustainable Energy for All (SE4ALL) initiative which is aimed at achieving three specific objectives which are: achieving universal access to modern energy services; doubling the global rate of improvement in energy efficiency; and doubling the share of renewable energy (RE) in the global energy mix from 18 to $36 \%$ [8]. Malawi just like many other developing countries in Africa has embraced and localised both the SE4ALL as well as the SDG 7 by integrating their provisions into the 2018 National Energy Policy (NEP) and adopting a national SE4ALL agenda $[9,10]$.

Increased energy investments shall be crucial if Malawi is to upgrade into a middle-income class nation in the next coming years. Modern energy also is a perquisite for attaining 
other development goals including eradication of hunger and poverty; increasing access to education, water and health; and reducing inequality among others thereby making it one of key areas for GoM's interventions as highlighted in the Malawi Growth and Development Strategy III (MGDS) [2, 11, 12]. All these factors therefore make the logic for expanding universal access to modern energy much stronger in the quest for global as well as national sustainable development [13].

Current available data shows that the world is making strides towards SDG 7; however not at the rate required for achieving the global goal as 789 million and 2.8 billion people in 2018 remained without access to electricity and clean cooking energy respectively [7]. Progress on achieving universal access to energy is much slower and thus contributing to the greatest energy deficit being experienced in Sub-Sahara African countries including Malawi where highest energy deficiency is recorded [7]. The country has a generation capacity of $482 \mathrm{MW}$ against a projected demand of $874 \mathrm{MW}$ for 2020 [1, 14]. This in effect has resulted to low energy access levels of about $11 \%$ percent out of a population of close to 17.5 million $[6,15]$.

On the other hand, biomass accounts for about $80 \%$ of national energy supply and 95 percent of the population in the country use firewood and charcoal for cooking and heating which is also blamed for contributing to high rates of deforestation. Furthermore, biomass usually is associated with indoor pollution that causes respiratory diseases, drudgery which collectively reduces the productivity of women and children $[10,16]$. Therefore, lack of modern energy services may help widen gender inequality which is not in line with the SDG 5, SDG 10 and the national gender policy.

In 2018, a global improvement was recorded regarding access to efficient cook stoves which is attributed to programmes undertaken by governments and development partners around the world [7]. In Malawi the Global Alliance for Clean Cook stoves (GACC), United Purpose (UP) and the United States Agency for International Development (USAID) are some of organisations which have actively been working on increasing the adoption of improved cook stoves technologies in the country [17]. However, the challenge on access to modern energy still stands as such there is a persuasive demand for radically tackling this challenge. The future economic growth also will depend on long term availability of energy resources that meet the national environmental objectives unlike the unclean and unsustainable sources of energy such as the imported petroleum which currently is being used to generate electricity amidst unreliable power supplies in Malawi [16].

\section{Policies and Regulations}

The GoM through the MGDS III recognises that universal access to modern energy will play a central role in improving and maintaining living standards of people. As such, more interventions to increase access to sustainable energy in the country are demanded [12]. The universal access to modern energy service provisions of SDG7 and the SE4ALL were also captured in the newly revised country NEP of 2018 [9]. This NEP further emphasises about the need for the creation of more through institutional and regulatory frameworks towards energy access goals.

In this perspective therefore, Malawi has also put in place several other national policies that coalesce the stipulated energy access ambitions of the NEP 2018. These include: the 2015 National Gender Policy (NGP) which advocates for equitable access to resources inclusive of energy in order to promote gender equality [18], the 2016 National Climate Change Management Policy (NCCMP) and the 2004 National Environmental Policy (NEP) which seek to promote access to RE and energy efficient technologies so as to conserve the environment $[19,20]$.

In order to create a good environment for the development of the energy sector, a number of regulatory frameworks have been adopted. However, more needs to be done in order to remove key policy barriers and further unlock the key opportunities for adapting cleaner, reliable and efficient renewable energy technologies [21]. This calls for stronger support for institutions governing the energy sector through increased technical capacity, financing, regulatory monitoring so as to map out a more comprehensive and achievable path for increased energy access as we progress towards the future.

Currently, there are strong indications that Malawi is far from achieving access to modern energy for all by the year 2030 in line with the SDG 7. Undertaking an autopsy therefore becomes so crucial if this unwelcome trend is to be reversed and take the country back on the desirable path. Therefore, this review paper seeks to confer Malawi's current status regarding access to modern energy, opportunities and challenges including policy, regulatory frameworks, institution capacity and energy resources that can impact government's efforts towards achieving the goal on access to modern energy. The review paper is therefore aimed at providing some insights to stakeholders including policy makers, investors, financing institutions and development organisations on how their collective efforts towards achieving universal access to modern energy can be enhanced.

\section{Defining Modern Energy and Universal Access}

\subsection{Modern Energy}

Defining modern energy is essential as it helps to emphasize that people around the globe need access to forms of energy that are cleaner, reliable and efficient for productive uses and improvement in quality of life [21]. Modern energy usually takes into account three sub themes which are: improved cook stoves and clean energy for household heating and cooking; electricity for lighting and powering equipment and appliances in homes and public facilities among others; and efficient mechanical power generated with the purpose of improving labour productivity [22]. With considerations that 
the household sector is the major consumer of energy accounting to $83 \%$ of the total Malawi energy demand [10, 23], this therefore justifies the need for government and development stakeholders' to focus on domestic energy needs in an effort to achieve universal access to modern energy services goal.

On a global scale modern energy has been associated more with electricity as it is most compatible with the needs of the modern economy [7]. However, Malawi endowed with different RE sources can adopt different energy technologies such as cleaner biofuels to meet goals on access to modern energy. The country has a diverse range of opportunities that can help meet the demand for modern energy through benchmarking from best practises being adopted globally, putting in place measures and policies that could among others encourage the adoption of local solutions that are affordable and sustainable in the long run.

\subsection{Universal Access}

Previously, defining energy access was an extremely complex task due to the difficulty in classifying the levels involved [24]. Energy access is entwined with complex socio-economic factors thus making it impossible to measure using the binary approach [11]. Currently, energy access is determined through integrated approaches based on either the on-ground household surveys and censuses or through the World Bank Multi-Tier Framework (MTF) which ranks energy access from tiers 0 to 5 [7]. Though both methods have widely been used, they both have different outcomes thus require that individual countries to consider primary data obtained for the local context. For instance, access to electricity in the MTF considers a number of attributes related to power supply that need to be satisfied which are power capacity, duration and availability, reliability, quality, affordability, legality, convenience, health and safety [24]. These provisions of all the aforementioned principles help streamline the long road towards energy access which has proved to have lasting impacts on reducing poverty, catalysing employment and economic growth at large.

\section{Status of Household Energy for Heating, Cooking and Lighting}

Biomass is mainly used for cooking and heating in Malawi [17]. This biomass fuel is further categorised into fuel wood and charcoal which account for $77 \%$ and $18 \%$ respectively. On the other hand, only $2 \%$ of the population uses electricity for cooking [25]. This is due to unaffordability of electricity as prices are prohibitive and due to high poverty levels which is characteristic of most developing countries. With no alternative sources of energy, most Malawians turn to charcoal, fuel wood and agricultural waste for cooking and heating [11, 25].

With regard to access of electricity, only $11 \%$ of Malawians are connected to the grid (Figure 2). The main use of electricity at household level is mainly for lighting [25]. The penetration of solar energy technologies in rural areas has proved to change the situation as more and more people prefer solar lanterns to paraffin lamps as the fuel is becoming unaffordable and not readily available. Biomass is still being used for lighting in most rural and remote areas (Figure 1) [25] but solar technology especially in the form of solar lanterns will definitely reach them sooner than later.

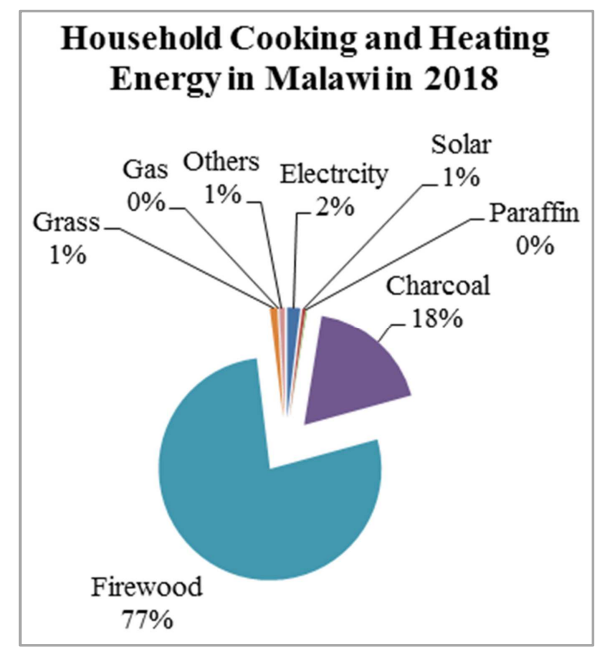

Figure 1. Household Cooking and Heating Energy in Malawi as of 2018; Source: [25].

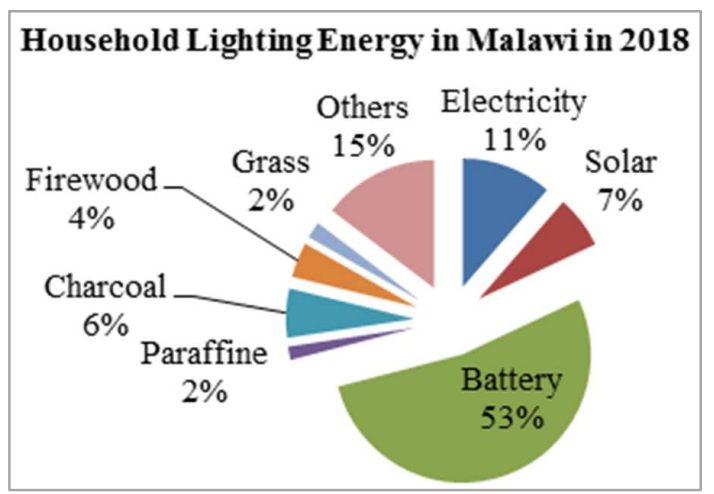

Figure 2. Household Lighting Energy in Malawi as of 2018; Source: [25].

\section{Drivers of Access to Modern Energy in Malawi}

\subsection{Improving Livelihoods}

Human development has been directly related to high energy consumption especially in developing countries [13, $16,27]$. Statistics show that there is a strong correlation between energy consumption and levels of socio-economic development of a country [28]. However, the situation is changing in developed countries as those with low per capita energy consumption have a higher Human Development Index (HDI) score which is attributed to efforts being made to address climate change and the need to reduce national energy footprint through energy efficiency [2]. Nevertheless, providing modern energy services to low-income households is considered to be so crucial when it comes to achievement of 
many other SDGs [23, 29].

\subsection{Climate Change and Environment}

Climate change has great impact on hydroelectricity generation dependent Malawi [10,30] as rivers in most parts of the country are dying up [31]. This makes the rationale for GoM to take a leading role in supporting global efforts in combating climate change by among others adopting green energy. The NEP already emphasizes on increasing the adoption of RE while reducing the overdependence on biomass which is blamed for high rates of deforestation, land degradation and siltation of rivers being experienced in the country $[27,32]$.

\subsection{Clean Cooking}

Inefficient cooking technologies such as the unprocessed biomass and traditional three-stone cook stoves in Malawi presents health risks as they are associated with indoor emissions that cause respiratory diseases [7]. The challenge becomes worse in female-headed families as often they lack financial muscle to pay for modern energy services due to sociocultural norms. Therefore, shifting to modern energy services will prove to be a solution that promotes good health apart from conserving the environment.

\subsection{Improving Access to Education}

The energy divide in the education sector mirrors in the national examination school performance as urban based schools usually outperform rural schools in Malawi [33]. Access to modern energy facilitates night studies (Figure 3a) $[10,23]$ and helps to retain teachers in rural areas [33]. In addition, ICT which demands electricity presents an opportunity to enhance education opportunities [33] thereby demanding for more investment in modern energy as an enabler. RE in this case can play a key role especially in rural

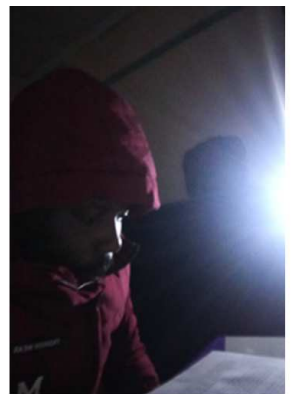

(a)

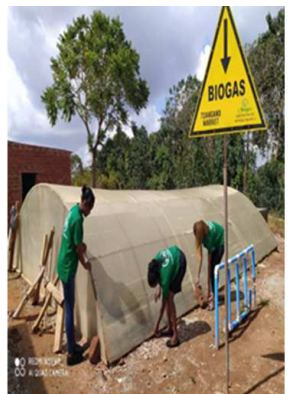

(b)

and isolated areas [23] as it is widely available and enables decentralised power generation.

\subsection{Improving Access to Health and Portable Water}

In a modern world energy affects all aspects development [29]; thereby making access to modern energy key for the achievement of the ambitious SDGs inclusive of the SDG 3 that seeks to ensure healthy lives and promote wellbeing for all by the year 2030 [10,23]. Increased access to electricity in rural areas of the country is widely considered as a solution for improving health service delivery in an energy deficit country [23]. Modern energy is demanded for health care service delivery at night, refrigeration, operation of some medical equipment and radio communication at health facilities. It is for this reason that in 2016 GoM through a Global Fund Project Implementation Unit embarked on a USD3.7 million project to develop solar PV Systems targeting 85 health facilities across the country [29]. In addition, modern energy is key when it comes to provision of portable water in rural communities as solar and wind water pumping systems are extensively being used to supply water to rural communities for household use [10, 29].

\subsection{Waste-to-Energy (WtE) Opportunities}

Waste management is emerging as a major challenge in major cities of Malawi due to inadequate collection and poor disposal methods which endangers the environment as well as human health $[34,35]$. Waste-to-Energy (WtE) is proving to be one of the sustainable methods for treating urban waste as it also enables recovery of energy that can be used for heating, cooking (Figure 3b) and electricity generation [36]. In Malawi, adoption of WtE is very crucial as it can contribute to the national goal on universal access to modern energy services while addressing sanitation, environment and climate change challenges [35].

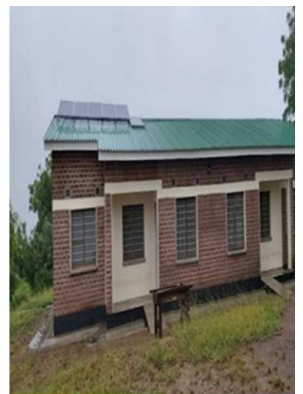

(c)

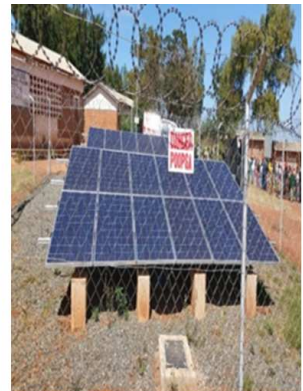

(d)

Figure 3. Modern energy technologies for institution and household lighting, cooking and heating in Malawi; Source: Authors.

\subsection{Agricultural Productivity and Food Security}

Rural electrification has lagged behind in the Sub-Sahara African countries thereby providing little opportunities for improved agricultural productivity [37]. Developing countries like Malawi must adopt energy intensive agriculture and food systems such as irrigation agriculture and mechanised farming in order to increase productivity and address food insecurity challenges [37]. In addition, there is a demand to promote the adoption of agro-processing and value addition which can increase income [32]. Currently, value addition to agricultural products in sub-Saharan African countries including Malawi is still very low, earning only USD 40 per tonne of the produce yet it is much higher in developed countries at USD180 per tonne [37]. Modern energy will also play a crucial role in helping the country reduce postharvest losses in an effort to promote food security and economic development [32]. 


\subsection{Employment Creation}

The energy industry can contribute to reducing unemployment rates at a time when countries globally are focusing on economic growth and job creation [2]. This sector widens the job creation opportunities that take the form of direct, indirect as well as induced jobs [4]. Usually, the energy industry directly provides fewer jobs as compared to other sectors of the economy; however studies in America have shown that the industry supports more indirect jobs partly due to long supply chains [4]. In Malawi, the charcoal business though mostly done illegally is a good example where its long supply chains comprising of charcoal producers, wholesalers, transporters and retailors employs many people [32].

\section{Prospects to Improving Access to Modern Energy in Malawi.}

\subsection{Energy Conservation and Efficiency}

Energy conservation (EC) means consuming less energy through behavioral changes. On the other hand, energy efficiency (EE) refers to the use of energy efficiently through the adoption of technologies that consume less power [5]. This definition is synonymous to that of UNEP which delineates to the provision of the same energy services yet using less energy [38]. Regarded as a "hidden fuel" or the "first fuel", the potential of EE can be tapped into for an increased access to energy. This in turn is envisaged to have lasting impacts on the socio-economic and environmental benefits towards sustainability [39] while also contributing to national energy security [5].

\subsection{Upgrading of Existing Power Infrastructure}

Currently, the power market in the South African Development Community (SADC) region is characterized by aging power infrastructure [40]. This is not exceptional in Malawi as $50 \%$ of the power plants in the country have already passed their expected lifespan and therefore transmission and distribution losses in the country remain one of the highest globally [16]. The aging and unreliable power infrastructure contributes to persistent power gap in the country and therefore presents a major obstacle to meeting the national goal of providing reliable modern energy services [9]. The GoM therefore seeks to upgrade the existing networks and power stations which are to be complemented by the development of new large-scale power generation in the country [24].

\subsection{Abundant Renewable Energy Resources}

Increasing the share of RE in the global mix is one of the three objectives aforementioned under the SE4ALL global agenda which has been localized by many countries including Malawi $[10,30]$. It is expected that in the SADC region, the share of RE will increase from $10 \%$ in 2010 to $46 \%$ in 2030 thus proving that $\mathrm{RE}$ is becoming an important resource for the diversification of the regional's energy mix [41]. To promote the development of RE, Malawi adopted a compressive energy policy that emphasizes on the need for an increased RE in the national energy mix [10]. The country seeks to take advantage of its abundant RE resources and the decline in the costs of RE technologies [11, 29]. The potentials of some RE resources in Malawi are as follows:

\subsubsection{Solar Resource}

SADC, the region where Malawi is located, generally has abundant solar radiation with 2500 sunshine hours per year that could enable a generation of up to $20,000 \mathrm{TWh}$ annually [29]. Malawi has an annual photovoltaic power potential of between 1315 and $1750 \mathrm{kWh} / \mathrm{m}^{2}$ with great potential in the north-western and central parts of the country (Figure 4) [42]. Despite having great potential for solar power generation the country has few installed solar PV Systems so far i.e. the 830kw on-grid PV System at Kamuzu International Airport [10]. In order to increase the role of solar energy in the national energy mix, the new energy policy of 2018 has emphasized on the need for deploying RE technologies including solar amidst unreliability of hydropower and increased demand for energy.
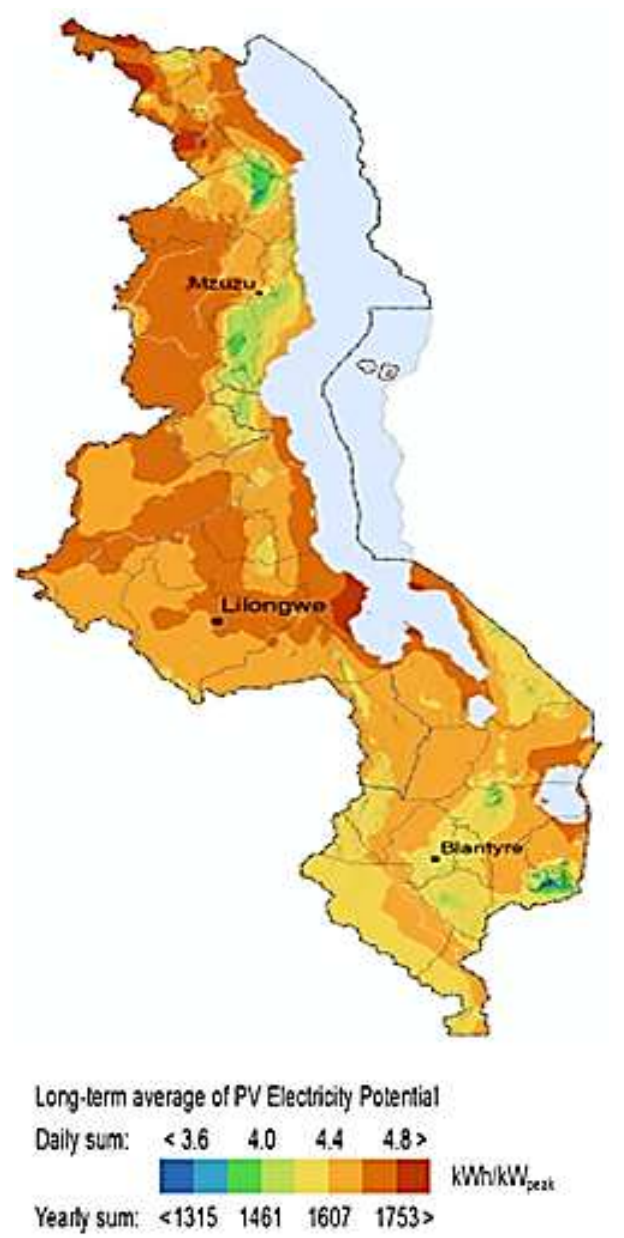

Figure 4. Solar Resource Map for Malawi; Source: [42].

\subsubsection{Hydro Resource}

Currently, hydropower is the backbone of the electricity 
generation in Malawi where Shire River accounts for $96 \%$ of electricity generated [41]. The GoM, in an effort to diversify the electricity sector came up with short, medium and long-term interventions which among others seek to invest into development of new hydropower schemes [14]. A number of potential sites were identified and studies done on twelve sites show that the country can be able to generate between 1,210 and $1570 \mathrm{MW}$ of hydroelectricity (Table 1).

Table 1. Hydro resource potential of Malawi; Source: [14].

\begin{tabular}{lll}
\hline River & Site on the River & Potential in MW \\
\hline Songwe & Monolo A and B & 300 \\
Bua & Mbongozi, Malenga, & 125 \\
Mpata Mmanga Gorge & Chasombo and Chizuma & \\
South Rukulu & - & 225 \\
North Rukulu & Lower Fufu Falls & 137.5 \\
Shire & Kayelekera & 10 \\
Dwambazi & Kholombizo & 370 \\
Henga Valley & Chimgonga & 50 \\
Rumphi & Vuku Vuku Falls & 30 \\
Fufu Falls High Dam & Njakwa & 15 \\
TOTAL & - & 127.5 \\
\hline
\end{tabular}

Note: some values in the table are averages of hydropower potential estimations made during feasibility studies on specific river sites.

\subsubsection{Wind Resource}

Though small geographically, Malawi has a Wind Resource Credit of $5 \%$ equaled to large countries such as Zambia because its wind resource is highly concentrated [41]. The country has a minimum annual average wind speed of $6.7 \mathrm{~m} / \mathrm{s}$, average cut-in-speed and rated speeds of 4 and $12 \mathrm{~m} / \mathrm{s}$ respectively [14]. Preliminary studies show that the wind resource in the country can be used on small scale mainly for milling of grains, irrigation, household water supply, and for lighting in rural areas of Malawi [16].

\subsubsection{Sustainable Biomass Resource}

Defining sustainable biomass is crucial at this point for Malawi at a time when overdependence on unsustainable charcoal and fuel wood is blamed for high deforestation rates [32]. In this case, urban and agricultural wastes which are generated in considerable quantities are regarded as renewable and sustainable energy resources in the long term [41]. The waste generated can be used to generate heat, electricity as well as other alternatives such us biogas and ethanol [36] thereby contributing to energy security and increased access to modern energy in Malawi.

\subsection{Governments Efforts to Liberalize Power Market}

Government owned power utilities in developing countries including Malawi have for long monopolized the Electricity Supply Industry (ESI) by controlling all levels of power supply chains [11]. Amidst the growing demand for capital in the energy sector, governments are looking for more involvement of the private sector thereby demanding for more reforms in order to liberalize the power market [40]. However, the dilemma still lies in achieving market liberalization while safeguarding the government's right to regulate the market in order to protect itself as well as consumers from commercial interests of the private investors [43].

GoM has been reforming the power sector in order to increase the availability of reliable electricity supply [43]. An IPP framework adopted by the GoM in 2017 led to restructuring of the power market and the unbundling of the government owned power utility, the Electricity Supply Corporation of Malawi (ESCOM) which to some extent has helped level the playing ground for IPPs in the country [43]. The Malawi Energy Regulatory Authority (MERA) has continued to pursue these provisions by putting in place cost recovery tariffs [44]. Following the unbundling of ESCOM the country has seen an increase in IPPs undertaking some feasibility studies in order to enter the electricity generation market [17].

\subsection{Regional Efforts Through the Southern African Power Pool (SAPP)}

The SADC in the energy sector seeks to ensure availability of adequate, reliable and affordable energy services in the region $[45,46]$. In 1995, the SADC in an effort to achieve energy sector objectives established the SAPP in order to co-ordinate planning and development of regional electricity interconnection by harmonising relationships between member utilities [30]. SADC has great potential for energy generation including RE [29], and since the resource base and level of electricity consumption in the region varies considerably from one country to another thereby motivating stronger integrated power transmission grids [47].

The power integration for the region also proves to be crucial if consumers are to be shielded from energy price variations arising from dependence on a single fuel [11]. SAPP helps to address the challenge of unequal distribution of energy resources within the region through trading of surplus power [46], thereby allowing countries with electricity deficits to access it from nearby countries [47]. Malawi can therefore reposition itself in such a way that it benefits more from the SAPP in order to achieve its goal of universal access to modern energy services bearing in mind that an addition of 26,108 MW of electricity is to be commissioned in the region between 2018 and 2022 [30]. To this end, Malawi is not connected to the South African Power Pool [48], however a project is underway to link the country to the SAAP via Mozambique through a $200 \mathrm{~km}$ transmission line from Matambo Substation in Mozambique to Phombeya in Blantyre City [1].

\subsection{Insufficient Technical Capacity}

At times the high demand for investments in physical capital overshadows that of human capital [49]. Malawi like many other developing countries has insufficient expertise in the energy sector especially in RE, thereby demanding for more investments in human resource development [44]. However, strides are being made to address this challenge through the promotion of RE and energy management related courses [17] some of which have been spearheaded by public 
universities like Mzuzu University, Polytechnic, Malawi University of Science and Technology (MUST) and some selected technical colleges.

\subsection{Climate Change Financing Opportunities}

Malawi is a party to the United Nations Framework Convention on Climate Change (UNFCC) and its Kyoto Protocol [19]. In order to meet its obligations, the country adopted the National Climate Change Investment Plan (NCCIP) that seeks to increase climate investment which shall help mobilise resources for RE development under the Clean Development Mechanisms [31]. At a time when establishment of new financial channels for RE is very slow mainly due to high investment risks, low tariffs, poor project implementation, tapping into continental climate funding opportunities will be crucial for developing countries such as Malawi [45]. Furthermore, for increased investments, collaborations and partnerships ought to be fronted to boost government support which are inclusive of; the private sector, developmental partners, Civil Society Organisations (CSOs) and carbon trading [31].

\section{Challenges Towards Increased Access to Modern Energy in Malawi}

\subsection{Policy and Regulatory Environment}

Progress towards improved access to modern energy demands long term determinations to strengthen policy and regulatory environment apart from having strong institutions that are able to enforce national regulations [27]. However, the existing legal, institutional frameworks and institution mechanisms still present a major barrier to the development of the energy sector in developing countries including Malawi especially in regard to RE [28]. Usually, national policies create environments that either can attract or scare away investors in the energy sector. For instance, investment policies influence allocation of risks, tariff setting and incentives which in turn have a positive correlation to the envisaged revenue associated with development of new infrastructure [43], an important aspect considered when making investment decisions [49]. While Malawi has made strides to improve the energy sector through policy and regulatory frameworks, several inherent challenges are still eminent and thereby demand for more government action.

\subsection{Environmental Factors}

The continued reliance on hydro for energy generation predisposes Malawi to adverse impacts of climate change due to droughts [50]. Malawi is one of countries which have been greatly affected by climate change as evidenced by droughts, floods and unpredictable rains which have severe ramifications on power generation. For instance, a drop in water levels of Shire River caused by prolonged draughts will subsequently reduce the production capacity and yet hydro power generation from this river alone accounts for almost $96 \%$ of the country's generation capacity [41].

\subsection{High Poverty Levels and Lack of Gender Inclusion in Energy Issues}

A certain percentage of the population in developing countries cannot afford to consume electricity even if they are connected to the grid due to high levels of poverty [11]. In SADC region it is proving that the already cheap electricity is unaffordable to many people because of high levels of poverty which also deters grid extension especially in rural areas [28]. In Malawi just like in many other countries around the globe, the problem is worse in female-headed households due to lack of financial capacity [51]. Therefore, rural electrification programmes may not have a great impact in promoting access to energy as long as the majority of the population i.e. rural population (14.7 million) remains not empowered economically $[25,28]$. The poor will continue to rely on unclean energy sources such as agricultural wastes which are cheap, easily accessible and can also be collected freely.

\subsection{Energy Financing Challenges}

Substantial funding is needed in the SADC region for energy infrastructure as well as human capital development in order to develop the energy sector and improve access to modern energy [29]. However, there is public debate that is focused on how to secure enough funding for access to modern energy amidst global financing challenges [27]. Considering the scale of capital needed in the energy sector developing countries have limited options and have since resorted to avenues that attract private investments which also demands government to reform the energy sector [43, 49].

Since the energy sector is ranked one of the most capital-consuming, concerted efforts in energy financing along several existing pathways are influential so as to meet the growing energy demand of the country [11]. It is estimated that by the year 2030, the power sector in Malawi will need 2.5 Billion USD and an addition of 600 Million USD for cooking to facilitate the transition towards the achievement of the universal access to modern energy services [6]. In order to attain the $31.6 \%$ rural energy access up from $4 \%$ as stipulated in the country Action Agenda, substantial multi-faceted investments in grid extension, power generation and human resource shall further these motives in the electricity sector [10].

As is common to many Sub-Saharan countries, poor investment climates are prevalent in Malawi too which hampers adequate and inherent support to boost its energy sector production capacity. Compounding this is the typically low and unstable energy demand mostly in the rural communities and households which does not stimulate private sector investments due to the level of uncertainty and associated risk in reaching the consumers ability and willingness to pay for the services provided [52]. Critical government support and collaborations with the private sector i.e. Independent Power Producers (IPPs) anchored on the pillar of increasing energy access through the penetration of 
RE technologies, biofuels for the transport sector and reduced biomass reliance for cooking shall help meet the demand for modern energy in the Malawi [29, 43].

\subsection{Technological Barriers}

The lack of technical expertise at different levels is one of major challenges affecting energy supply in Malawi. Generally, the country is faced with low levels of technical expertise which consequently necessitates the companies entering the power market to train their technical staff first, which is expensive too [53]. The problem is worse in rural areas where the need is huge as most qualified engineers are located in urban areas with better pay checks. Therefore, most installations in rural areas are done by unqualified technicians thus contributing to substandard work and unreliability of the energy systems.

\section{Conclusions}

Energy access to modern energy plays an important role in socio-economic development of a country as energy is demanded by almost all sectors of an economy. However, Malawi is still far from achieving universal access to modern energy, thereby requiring the country to make some radical changes in order to achieve its intended goal on energy. The country needs to improve its policies, regulatory frameworks and enforcement of the regulations. The country still has to diversify its sources of energy and more detailed studies regarding energy resource potential needs to be done so that the required data is made available for use by the potential investors. At a time when getting capital for investment in the power sector is not easy, there is a need for the GoM to adopt the most cost effective interventions such as energy efficiency and upgrading of the existing power infrastructure before considering investing into new power plants.

\section{Recommendations}

Malawi needs to diversify its sources of energy in order to improve access to energy by taking advantage of its abundant $\mathrm{RE}$ resources such as solar, wind, hydropower and urban waste in order to attain the envisaged $30 \%$ electricity access by 2030 .

Amidst energy financing challenges the country should look at the most cost-effective options for increasing access to modern energy including energy efficiency and conservation; and upgrading of the existing power infrastructure.

Access to modern energy services demands an integrated approach therefore Malawi should also consider adopting some locally generated solutions that are more affordable and sustainable. This may help address sustainability challenges resulting from the country's limited capacity to finance, develop, operate and maintain the imported technologies.

Access to energy in the country among others is hindered by high levels of poverty as people are unable to purchase the already subsidised electricity. People will still prefer for free and unclean energy sources such as agricultural waste. The country therefore needs to empower communities economically if the ambitious goal of universal access to electricity is to be achieved.

The government must align electricity investment plan with rural development goals in order to address the challenge of attracting private investment in places that are commercially unattractive.

\section{References}

[1] WB, (2019). Malawi: Electricity Access Project, World Bank.

[2] ESMAP (2017). State of Electricity Access Report, Energy Sector Management Assistance Program, Washington. USA.

[3] Anna Lerner, Z. V. Dalphond, M. Gee, T. Plagge (2017). Energy Analytics for Development: Big Data for Energy Access, Energy Efficiency, and Renewable Energy, Energy Sector Management Assistance Program. Washington, DC: World Bank.

[4] WEF (2012). Energy for Economic Growth: Energy Vision Update 2012, World Economic Forum. Geneva, Switzerland.

[5] R. Banerjee (2015). Int. J. Innov. Res. Adv. Eng. 2, 186-190.

[6] E. Borgstein, S. Santana, B. Li, K. Wade, E. Wanless (2019). Malawi Sustainable Energy Investment Study: Summary for Decision Makers, Rocky Mountain Institute.

[7] IEA IRENA UNSD WB WHO (2020). Tracking SDG7: The Energy Progress Report 2020, International Energy Agency, International Renewable Energy Agency, United Nations Statistics Division, World Bank and World Health Organization.

[8] UN SE4ALL (2012). Sustainable Energy for All: A Global Action Agenda., Sustainable Energy for All.

[9] MoNREM (2018). National Energy Policy, Ministry of Natural Resources, Energy and Mining, Government of Malawi.

[10] Deloitte (2017). SE4ALL Action Agenda, Government of Malawi.

[11] N. Avila, J. Carvallo, B. Shaw, D. M. Kammen (2017). The Energy Challenge in Sub-Saharan Africa: A Guide for Advocates and Policy Makers, Oxfam Research Backgrounder Series.

[12] MoFEPD (2017). The Malawi Growth and Development Strategy (MGDS) III (2017 - 2022), Ministry of Finance, Economic Planning and Development. Government of Malawi.

[13] S. Pachauri, N. D. Rao, Y. Nagai, K. Riahi (2012). Access to Modern Energy: Assessment and Outlook for Developing and Emerging Regions, International Institute for Applied Systems Analysis (IIASA), United Nations Industrial Development Organization (UNIDO).

[14] MoNREE (2010). Malawi Electricity Investment Plan, Ministry of Natural Resources, Energy and Environment. Government of Malawi.

[15] NSO (2018). 2018 Malawi Population \& Housing Census: Preliminary Report, National Statistical Office. 
[16] J. L. Taulo, K. J. Gondwe, B. Sebitosi (2015). J. Energy South. Africa 26, 19-32.

[17] CCEE (2019). Energy Efficiency Brief: Malawi, Copenhagen Centre on Energy Efficiency.

[18] MoGCDSW (2015). National Gender Policy, Minister of Gender, Children, Disability and Social Welfare. Malawi.

[19] MoNREM (2016). National Climate Change Management Policy, Ministry of Natural Resources, Energy and Mining. Government of Malawi.

[20] MoNREA (2004). National Environmental Policy, Ministry of Natural Resources and Environmental Affairs, Government of Malawi.

[21] REN21 (2019). Renewables 2019 Global Status Report, (Paris: REN21 Secretariat). ISBN 978-3-9818911-7-1.

[22] SE4ALL (2015). Progress Toward Sustainable Energy: Global Tracking Framework 2015 Summary Report, Sustainable Energy for All.

[23] MEM (2017). Malawi Renewable Energy Strategy, Ministry of Energy and Mining.

[24] M. Bhatia, N. Angelou (2015). Beyond Connections: Energy Access Redefined, The World Bank: Washington, DC, USA.

[25] NSO (2019). 2018 Malawi Population and Housing Census: Main Report, National Statistical Office.

[26] C. Kamunda, Malawi (2014). J. Sci. Technol. 10, 53-58.

[27] ESMAP (2018). Regulatory Indicators for Sustaninable Energy (RISE), ESMAP Report. Washington, DC: World Bank.

[28] K. Waagsaether (2014). An Overview of the Energy Picture for SADC Countries, with a Focus on Renewable Energy, Southern African Faith Communities' Environment Institute.

[29] SADC SARDC (2018). SADC Energy Monitor 2018, Southern African Development Community, Southern African Research and Documentation Centre.

[30] SAPP (2018). Annual Report, Southern African Power Pool.

[31] MoECCM (2013). National Climate Change Investment Plan 2013-2018, Ministry of Environment and Climate Change Management. Malawi.

[32] MoAIWD (2016). National Agriculture Policy 2016, Ministry of Agriculture, Irrigation and Water Development. Lilongwe, Malawi.

[33] A. Welland (2017). Education and the Electrification of Rural Schools, Technical report 13. Smart Villages.

[34] F. C. Eboh, B.-åke Andersson, T. Richards (2019). Waste Manag. 100, 75-83.

[35] H. Chamdimba, R. G. Mugagga, E. O. Ako (2020). J. Energy Res. Rev. 4, 44-57.

[36] K. Funk, J. Milford, T. Simpkins (2013). Waste Not, Want Not: Analyzing the Economic and Environmental Viability of Waste-to-Energy (WtE) Technology for Site-Specific
Optimization of Renewable Energy Options, Technical Report. NREL/TP-6A50-52829.

[37] S. G. Banerjee, K. Malik, A. Tipping, J. Besnard, J. Nash (2017). Double Dividend: Power and Agriculture Nexus in Sub-Saharan Africa, International Bank for Reconstruction and Development.

[38] UNEP (2016). Guide for Energy Efficiency and Renewable Energy Laws, United Nations Environment Programme. Nairobi, Kenya.

[39] UNECE UNEP DTU (2017). Overcoming Barriers to Investing in Energy Efficiency, United Nations Economic Commision for Europe.

[40] Promethium Carbon (2016). Electricity Market Reform in Southern Africa, Johannesburg.

[41] A. Miketa, B. Merven (2013). Southern African Power Pool: Planning and Prospects for Renewable Energy, International Renewable Energy Agency.

[42] ESMAP (2017). Solar Resource Mapping in Malawi: Annual Solar Resource Report, Energy Sector Management Assistance Program | The World Bank.

[43] MoNREM (2017). Independent Power Producer (IPP) Framework for Malawi, Ministry of Natural Resources, Energy and Mining, Republic of Malawi.

[44] MERA (2020). Strategic Plan 2020 - 2024, Malawi Energy Regulatory Authority.

[45] SADC SARDC (2016). SADC Energy Monitor 2016: Baseline Study of the SADC Energy Sector, Southern African Development Community, Southern African Research and Documentation Centre. Gaborone, Harare.

[46] M. Chanakira (2011). in: Rev. Strateg. Intell. Int. Relations, pp. 64-78.

[47] A. Medinilla, B. Byiers, K. Karaki (2019). African Power Pools: Regional Energy, National Power, ECDPM Discussion Paper No. 244.

[48] WB (2019). Implementation, Completion and Results Report: Report No: ICR00004654, World Bank.

[49] O. Johnson, C. Muhoza, P. Osano, J. Senyagwa, S. Kartha (2017). Catalysing Investment in Sustainable Energy Infrastructure in Africa: Overcoming Financial and Non-Financial Constraints, Working Paper 2017-03. Stockholm Environment Institute. Stockholm.

[50] O. Kachaje, V. Kasulo, G. Chavula (2016). African J. Environ. Sci. Technol. 10, 476-484.

[51] WB (2019). Energy Vulnerability in Female-Headed Households: Findings from the Listening to Citizens of Uzbekistan Survey, International Bank for Reconstruction and Development / The World Bank.

[52] N. J. Williams, P. Jaramillo, J. Taneja, T. Selim (2015). Renew. Sustain. Energy Rev. 52, 1268-1281.

[53] ODI (2016). Accelerating Access to Electricity in Africa with off - Grid Solar, Overseas Development Institute, London. 